Vol. 11 (1): 149-158 (2021)

\title{
MODERN TRENDS OF FORMATION OF THE FORESTS IN RIVERS BASINE WHICH PROVIDE THE STABILITY OF GIDROLOGICAL REGIME OF LAKE BAIKAL (EAST SIBERIA)
}

\author{
Alexander Sizykh \\ Siberian Institute of Plant Physiology and Biochemistry SB RAS, 664033, Irkutsk, 132, Lermontova str., Russia; \\ "Corresponding Author Alexander Sizykh, e-mail: alexander.sizykh@gmail.com;
}

Received December 2020; Accepted January 2021; Published February 2021;

DOI: https://doi.org/10.31407/ijees11.121

\begin{abstract}
Due to this fact, it is especially important to establish the peculiarities of spatial-temporal variety of forests structure in the context of modern trends in environmental studies, where it is necessary to obtain information mass (quantitative and qualitative ones) in order to forecast the way of forests development in the basins of rivers forming hydrologic regimes of lakes on the background of climatic fluctuations at the regional-topological level of environmental organization. Finding out of structural-dynamic organization of forests in the basins of rivers flowing into Lake Baikal will allow find out in time probable changes in lake hydrologic regimes with time.
\end{abstract}

Keywords: modern trends of forest formation, rivers basin, hydrological regimes, Lake Baikal, East Siberia 